CLINICAL STUDY

\title{
Testosterone but not estradiol level is positively related to muscle strength and physical performance independent of muscle mass: a cross-sectional study in 1489 older men
}

\author{
Tung Wai Auyeung ${ }^{1}$, Jenny Shun Wah Lee ${ }^{2}$, Timothy Kwok ${ }^{2}$, Jason Leung ${ }^{3}$, Claes Ohlsson ${ }^{4}$, Liesbeth Vandenput ${ }^{4}$, \\ Ping Chung Leung ${ }^{3}$ and Jean $W_{0 o}^{2}$ \\ ${ }^{1}$ The S H Ho Centre of Gerontology and Geriatrics, ${ }^{2}$ Division of Geriatrics Medicine, Department of Medicine and Therapeutics and ${ }^{3} 3 / F$, School of Public \\ Health, Jockey Club Centre for Osteoporosis Care and Control, The Chinese University of Hong Kong, Shatin, Hong Kong, People's Republic of China and \\ ${ }^{4}$ Division of Endocrinology, Department of Internal Medicine and Geriatrics, Institute of Medicine, Centre for Bone Research at the Sahlgrenska Academy, \\ University of Gothenburg, SE-41345 Gothenburg, Sweden
}

(Correspondence should be addressed to TW Auyeung; Email: auyeungtw@gmail.com)

\begin{abstract}
Objective: To examine the relationship between different measures of testosterone and estradiol $\left(\mathrm{E}_{2}\right)$, muscle mass, muscle strength, and physical performance; and to test whether the association of sex hormone level with muscle strength and physical performance was independent of muscle mass.

Design and methods: A cross-sectional survey on 1489 community-dwelling men older than 64 years of age. Serum levels of testosterone and $\mathrm{E}_{2}$ were measured by mass spectrometry, and sex hormonebinding globulin (SHBG) levels were measured by immunoradioassay. Muscle mass was examined by dual-energy X-ray absorptiometry and physical performance was assessed by hand-grip strength, gait speed, step length and chair-stand test.

Results: Appendicular skeletal mass (ASM) was positively associated with total testosterone (TT; $P<0.001)$, free testosterone (FT; $P<0.001)$, and total $\mathrm{E}_{2}(P<0.001)$ but not with free $\mathrm{E}_{2}(P=0.102)$. After adjustment for age, serum SHBG and relative ASM, both TT and FT were significantly associated with grip strength, narrow-walk speed and the composite neuromuscular score. Higher total $\mathrm{E}_{2}$, but not free $E_{2}$ was associated with lower grip strength $(P<0.05)$ after adjustment for age, FT, SHBG and relative ASM.

Conclusions: Testosterone level was related to both muscle mass, strength and physical performance. Total $\mathrm{E}_{2}$ level, though related to muscle mass positively, affected muscle strength adversely in older men.
\end{abstract}

European Journal of Endocrinology 164 811-817

\section{Introduction}

Several studies have examined the inter-relationship between various measures of testosterone level, muscle mass and muscle strength (1-6). In men aged 65 or older, Baumgartner et al. (1) reported that free testosterone index, but not total testosterone (TT) level, was modestly associated with muscle mass, whereas Iannuzzi-Sucich et al. (2) demonstrated that muscle mass was correlated to bioavailable testosterone (BioT), leg strength and physical performance. However, in another cohort of healthy older men, Van den Beld et al. (3) reported that testosterone level, as represented by TT and BioT, was related to muscle strength but not to muscle mass. On the other hand, Roy et al. (5) observed that TT and BioT were positively correlated with both the muscle mass and strength, yet after adjustment for muscle mass, they were no longer independently associated with muscle strength. Szulc et al. (4) had compared the muscle mass and physical performance of hypogonadal and eugonadal men and found that hypogonadal men exhibited impaired static and dynamic balance despite relatively preserved muscle mass. Similarly, Orwoll et al. (6) have observed that testosterone level was related to physical performance and fall risk but not to muscle mass. Although the effect of testosterone supplementation on muscle mass and strength was less controversial in interventional studies (7-14), whether endogenous testosterone was related to muscle mass alone, muscle strength alone, or both; and which measures of endogenous testosterone best related to muscle mass and strength had been inconsistent.

In addition, the association of muscle mass and strength with endogenous estrogen level in older men has scarcely been examined. It was reported that two 
studies observed no correlation between estradiol $\left(\mathrm{E}_{2}\right)$ and muscle mass $(3,15)$, whereas Vandenput et al. (16) have recently reported a positive association between lean mass and $E_{2}$ in elderly Swedish men.

We have reported that cognitive impairment was adversely associated with muscle strength and physical performance independent of muscle mass, and have postulated that the co-existing sex hormone decline in cognitively impaired older adults $(17,18)$ might account for this observation (19). In this study, we hypothesized that endogenous sex hormone level, similar to cognitive function, might affect both muscle quantity (lean mass) and quality (muscle strength and physical performance). We therefore, attempted to examine the relationship among different measures of testosterone and $\mathrm{E}_{2}$, muscle mass, muscle strength and physical performance; and to test whether the association of sex hormone level with muscle strength and physical performance was independent of muscle mass.

\section{Methods}

\section{Study population and measurements}

Participants were from the MrOS Hong Kong cohort, which form part of the study of Osteoporotic Fractures in Men (MrOS) (20) together with subjects from the US and Sweden. Details of the Hong Kong cohort have been described elsewhere (21). In brief, 2000 Chinese men aged 65 years and above who were ambulant without assistance from another person were invited to the study center for a comprehensive health check. Stratified sampling was adopted to achieve $\sim 33 \%$ of participants in each of the three age groups: 65-69, $70-74$, and $\geq 75$ years. The method of recruitment consists of notices placed in housing estates and community centers all over Hong Kong.

The average grip strength was measured using both hands (Jamar Hand dynamometer 5030 J1, Sammons Preston, Inc., Bolingbrook, IL, USA). We performed four other neuromuscular tests. Subjects were asked to stand up with folded arms from a chair five times and the time required was recorded. The time to walk $6 \mathrm{~m}$ at normal pace, with and without a $20 \mathrm{~cm}$ wide boundary, was measured. The number of steps to complete the 6-m walk without the $20 \mathrm{~cm}$ boundary was counted to derive the step-length. Subjects who failed to perform or complete a particular neuromuscular test had to be excluded from the analysis of that individual test. To include these subjects who might represent the worst neuromuscular function group (being unable to complete a test), a performance-based physical function scoring method was adopted from Wang et al. (22). Each neuromuscular test result was assigned a score of 0 if the subject was not able to complete the test, and 1-4 according to the quartiles of the neuromuscular performance. The scores of the five tests were summated into one neuromuscular composite score which ranged from 0 to 20, with 20 representing the best performance.

Stature and body weight were measured to calculate body mass index (BMI; body weight in kilograms divided by the square of stature in meters). The subjects were asked to stand upright without shoes and look straight ahead with standing heights measured by the Holtain Harpenden Stadiometer (Holtain Ltd, Crosswell, UK). Body weight was measured, with the subjects wearing a light gown, by the Physician Balance Beam Scale (Healthometer, Alsip, IL, USA).

We measured muscle mass using dual-energy X-ray absorptiometry (DXA) using a Hologic QDR 2000 densitometer (Hologic, Waltham, WA, USA). Appendicular skeletal mass (ASM) was calculated by the summation of muscle mass measured in the four limbs, with the operator adjusting the cut lines of the limbs according to specific anatomical landmarks as described by Heymsfield et al. (23). Calibration with a Hologic body composition step phantom was performed at least three times per week. The method has been described in detail in other reports of the same cohort of older adults $(19,24)$. Muscle mass was corrected for body size by dividing the ASM with the square of stature $(1,2,25)$ and was termed relative ASM.

A random subpopulation consisting of 1489 men had fasting venous sampling from 0800 to $0900 \mathrm{~h}$ for assay of sex steroid hormones. Serum was stored at $-80{ }^{\circ} \mathrm{C}$ and then transported by courier service to Quebec, Canada, for assay in dry ice $\left(-78.5^{\circ} \mathrm{C}\right)$.

\section{Laboratory methods}

A validated gas chromatography mass spectroscopy system $(26,27)$ was used for analysis of sex steroids at the CHUL Medical Research Center, Quebec, Canada: testosterone (limit of detection, $0.05 \mathrm{ng} / \mathrm{ml}$; intra-assay coefficient of variation (CV), $2.9 \%$; inter-assay CV, 3.4\%) and $\mathrm{E}_{2}$ (limit of detection, $2.00 \mathrm{pg} / \mathrm{ml}$; intra-assay $\mathrm{CV}$, $1.5 \%$; inter-assay CV, 2.7\%). A 50\% phenyl-methyl polysiloxane (DB-17HT) capillary column $(30 \mathrm{~m}$ $\times 0.25 \mathrm{~mm}$ internal diameter; $0.15-1.0 \mu \mathrm{m}$ film thickness) with helium as carrier gas was used. The analytes and the internal standard were detected using a HP5973 quadrupole mass spectrometer equipped with a chemical ionization source. Serum sex hormonebinding globulin (SHBG) was measured using IRMA (Orion Diagnostics, Espoo, Finland; limit of detection $1.3 \mathrm{nmol} / \mathrm{l}$, intra-assay CV, 3\%; inter-assay CV, 7\%). Free fractions of testosterone were calculated as described by Van den Beld et al. (3), taking the concentration of TT, total $E_{2}$ and SHBG into account, and assuming a fixed albumin concentration of $43 \mathrm{~g} / \mathrm{l}$.

\section{Statistical analysis}

The relationship between muscle mass (ASM/height ${ }^{2}$ ) and testosterone level (FT and TT) was analyzed by 
Table 1 Sex hormone level, muscle mass and physical performance of the participants.

\begin{tabular}{lrr}
\hline & Mean & \multicolumn{1}{c}{ s.D. } \\
\hline Age (years) & 72.52 & 4.99 \\
Height (cm) & 163.01 & 5.71 \\
Weight $(\mathrm{kg})$ & 62.13 & 9.41 \\
BMl & 23.35 & 3.15 \\
ASM $(\mathrm{kg})$ & 19.10 & 2.62 \\
Relative ASM & 7.17 & 0.82 \\
Total testosterone $(\mathrm{ng} / \mathrm{ml})$ & 5.47 & 2.05 \\
Free testosterone $(\mathrm{ng} / \mathrm{dl})$ & 10.60 & 3.05 \\
Total $\mathrm{E}_{2}(\mathrm{pg} / \mathrm{ml})$ & 24.63 & 14.37 \\
Free $\mathrm{E}_{2}(\mathrm{pg} / \mathrm{ml})$ & 0.58 & 0.40 \\
SHBG $(\mathrm{nmol} / \mathrm{l})$ & 51.17 & 20.36 \\
Grip strength $(\mathrm{kg})$ & 30.98 & 6.57 \\
Timed 5 chair-stand (s) & 12.69 & 3.93 \\
Step-length (m) & 0.57 & 0.08 \\
Walk speed (m/s) & 1.02 & 0.22 \\
Narrow-walk speed $(\mathrm{m} / \mathrm{s})$ & 0.91 & 0.25 \\
Neuromuscular composite & 12.12 & 4.09 \\
score & & \\
\hline
\end{tabular}

multiple linear regression with adjustment for age, SHBG and BMI, since BMI is a major determinant of muscle mass $(19,24)$. In analyzing $\mathrm{E}_{2}$ (total and free $\mathrm{E}_{2}$ ), additional adjustments were undertaken for FT since $E_{2}$ was transformed from testosterone aromatization. In analyzing the association between grip strength and physical performance tests with testosterone and $\mathrm{E}_{2}$ level, multiple linear regressions were employed with the test performance as the dependent variable and different measures of sex hormone as the independent predictor. The regression was then repeated with adjustment for age alone and then for age, SHBG and muscle mass (ASM/height ${ }^{2}$ ) for testosterone; and additional adjustment for FT for total and free $E_{2}$. All tests were two-sided and a $P$ value $<0.05$ was taken as statistically significant.

\section{Results}

Table 1 shows the sex hormone levels, relative ASM, and physical performance of the participants. Relative ASM was positively related to TT, FT, and total $\mathrm{E}_{2}$ but not to free $\mathrm{E}_{2}$ level with adjustment for age, BMI and SHBG (Table 2). Higher FT level was consistently associated with stronger grip strength, better performance in all physical tests, and higher composite neuromuscular score before adjustment (Table 3). After adjustment, the associations remained significant between higher FT and grip strength, narrow-walk speed, and the composite neuromuscular score (Table 3). Higher TT level was associated with shorter step-length and faster narrow-walk speed before adjustment (Table 3). After adjustment, TT was associated with stronger grip strength, faster narrow walk speed and higher neuromuscular score (Table 3). Despite a positive association between total $\mathrm{E}_{2}$ and relative ASM (Table 2), total $\mathrm{E}_{2}$ was negatively associated with grip strength after adjustment for age, SHBG, FT, and relative ASM (Table 4).

\section{Discussion}

Compatible with the results of other reports (1-6), we observed a positive correlation between endogenous testosterone level and stronger muscle strength and better physical performance. The effect size was modest (Table 3), and it is therefore not certain whether they may be translated into clinical benefit, such as reduction in fall risk, improved quality of life or better survival. However this favourable effect of testosterone on muscle strength and physical performance was independent of muscle mass, implying that testosterone affected not only the quantity but also the quality of muscles.

We have demonstrated that cognitive impairment could adversely affect muscle strength and physical function independent of muscle mass (19). As at least two of the physical performance tests, grip strength (28) and gait speed (29) have been observed to be closely related to cognitive function in past studies, and that sex hormone decline and cognitive function may be closely related $(17,18)$, it is therefore plausible that testosterone decline may be the common factor that links cognitive impairment with muscle loss and weaker strength in older men. However, the relative importance of sex hormone and cognition in determining muscle mass and muscle performance remained elusive. In addition, the effect of androgen on motor neuron has been demonstrated in some animal studies, in which motor neuron size was reduced in castrated mice. It is therefore plausible that the efficiency or quality of muscle contractility can be adversely affected by the co-existing motor neuron atrophy related to sexhormone decline $(30,31)$.

Age-adjusted TT was negatively associated with weaker grip strength. This paradoxical relationship reverted after adjustment for SHBG, which had a significant negative effect on muscle strength ( $\beta$-coefficient: $-0.044, P<0.001$; data not shown).

Table 2 Relationship between sex hormone level and relative ASM.

\begin{tabular}{|c|c|c|c|}
\hline & Unit (S.D.) & $\begin{array}{l}\text { Difference in } \\
\text { relative ASM }\left(\mathrm{kg} / \mathrm{m}^{2}\right) \\
\text { per unit }(\mathrm{s} . \mathrm{D} .) \\
\text { change }(95 \% \mathrm{Cl})^{\mathrm{a}}\end{array}$ & $P$ value \\
\hline Total testosterone ${ }^{a}$ & $2.05 \mathrm{ng} / \mathrm{ml}$ & $0.1(0.06,0.13)$ & $<0.0001$ \\
\hline Free testosterone ${ }^{a}$ & 3.05 ng/dl & $0.08(0.05,0.1)$ & $<0.0001$ \\
\hline Total $\mathrm{E}_{2}^{\mathrm{b}}$ & $14.37 \mathrm{pg} / \mathrm{ml}$ & $0.04(0.02,0.07)$ & 0.0009 \\
\hline Free $E_{2}^{b}$ & $0.40 \mathrm{pg} / \mathrm{ml}$ & $0.02(-0.01,0.05)$ & 0.1028 \\
\hline
\end{tabular}

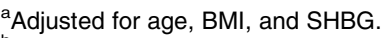

${ }^{\mathrm{b}}$ Adjusted for age, BMI, FT, and SHBG. 


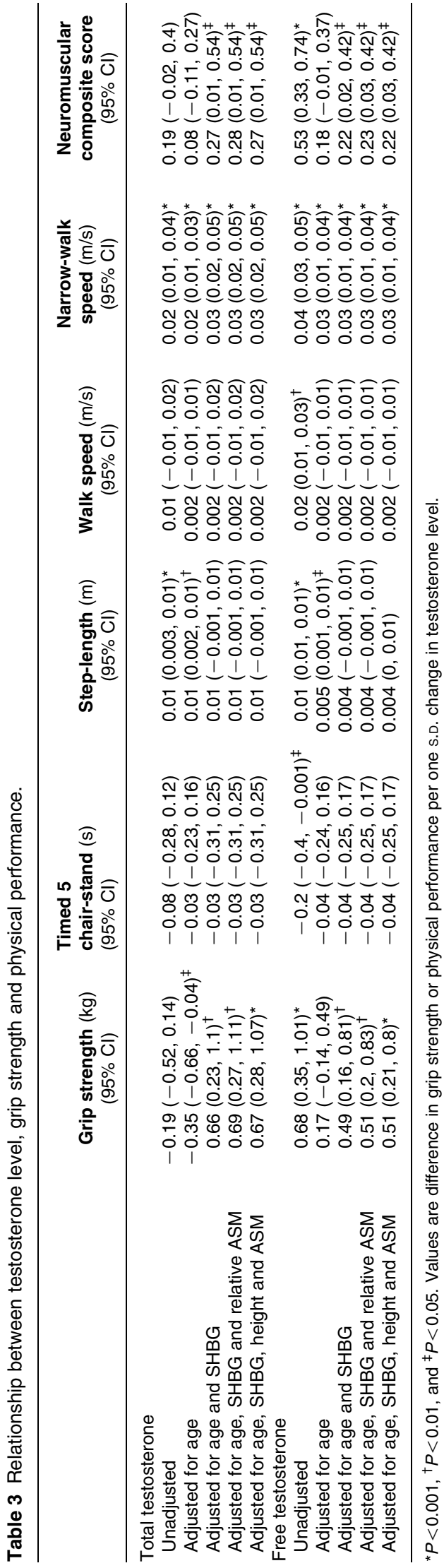

In contrast to two previous reports that failed to demonstrate any association between endogenous estrogen and muscle mass $(3,15)$, we found a positive correlation between total $E_{2}$ but not free $E_{2}$ and relative ASM. This agreed partially with the recent work done by Vandenput et al. (16), in which muscle mass was observed to be associated positively with both total and free $E_{2}$. In addition, this positive relationship was unrelated to the testosterone level as the association persisted after its adjustment (Table 2). The role of estrogen receptor activation in the modulation of muscle mass remains unclear although some animal studies have revealed that estrogen receptor activation was involved in this process (32-34). Our results also revealed that total $\mathrm{E}_{2}$ level, though positively related to muscle mass, was negatively related to muscle strength (Tables 2 and 4), in contrary to testosterone that was associated favorably with both muscle quantity and quality. Total $\mathrm{E}_{2}$ had no effect on grip strength before adjustment but had a negative effect after adjustment for age, SHBG, FT, and relative ASM. The negative effect of total $E_{2}$ on grip strength might have been confounded by its positive association with muscle mass, which could only be revealed after adjustment for ASM. The mechanistic explanation of this negative effect of $E_{2}$ on muscle quality remains elusive.

The testosterone level in our subjects was higher than the Swedish MrOS cohort (16). This observation is consistent with the racial and geographical variations in sex steroid levels reported among Asians from Japan (35). It is likely that Chinese in Hong Kong, also had higher testosterone level than the Caucasian and Black populations due to the same reason. In addition, our sample was recruited by voluntary participation, in contrary to the Swedish MrOS subject, which was recruited by population-based random sampling. Our subjects might therefore be healthier and more active. Contrary to the Swedish MrOS cohort (16), but in consistent with other studies (1-6), we have demonstrated a positive relationship between testosterone and muscle mass. We have used appendicular lean mass corrected for body size instead of the un-corrected total body lean mass and leg lean mass in the Swedish MrOS. The inclusion of trunk lean mass, which may be less testosterone dependent, and the use of lean mass un-corrected for body size might have diluted the testosterone effect in the Swedish study.

Our study had several limitations. The participants were all independent community-living older men. Our results, therefore, cannot be extrapolated to the frail or institutionalized older adults, in whom sex hormone decline may be disease associated rather than ageassociated, and in whom the relationship of sex hormone with muscle mass, muscle strength and physical performance may be different. The presence of intramuscular adipose tissue renders DXA measurement of muscle mass less accurate when compared with the magnetic resonance imaging method (36). 


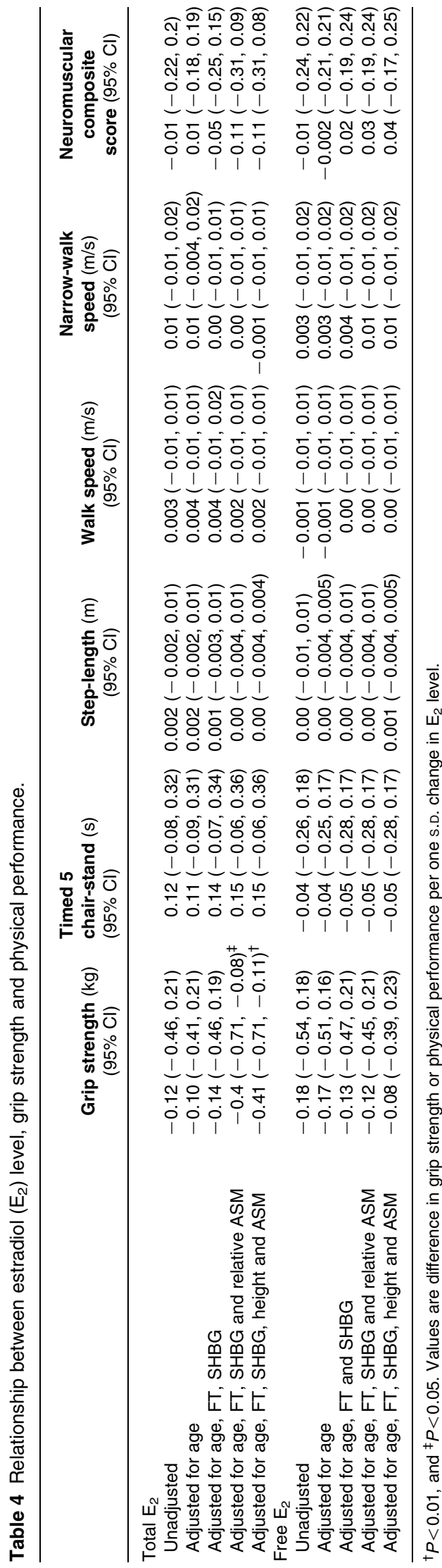

The physical performance tests that we employed may have a ceiling effect and cannot differentiate subtle functional impairment, therefore a modest relationship between sex-steroids and physical performance could have been missed. The use of calculated free sex-steroids instead of directly measured ones may lack accuracy, particularly in large population studies (37). However, the Vermeulen method that we employed has been demonstrated to have generally small deviations from the multi-ligand model method proposed by Mazer et al. (38). The validity of $\mathrm{E}_{2}$ as a biological variable has never been tested in men, though calculated free $\mathrm{E}_{2}(39,40)$ and FT (40) were closely related to directly measured sex-steroids and were valid predictors of cancer risk in women. Being cross-sectional, the association observed does not imply any causal relationship between testosterone decline and poor muscle performance.

\section{Conclusion}

Testosterone was related to both muscle quantity and quality. It was positively correlated with muscle mass and was associated with muscle strength and physical performance independent of muscle mass. Total $\mathrm{E}_{2}$ level, though related to muscle mass positively, was associated with weaker muscle strength in older men.

\section{Declaration of interest}

The authors declare that there is no conflict of interest that could be perceived as prejudicing the impartiality of the research reported.

\section{Funding}

This work was supported by the Hong Kong Research Grant Council.

\section{References}

1 Baumgartner RN, Waters DL, Gallagher D, Morley JE \& Garry PJ. Predictors of skeletal muscle mass in elderly men and women. Mechanisms of Ageing and Development $1999 \quad 107$ 123-136. (doi:10.1016/S0047-6374(98)00130-4)

2 Iannuzzi-Sucich M, Prestwood KM \& Kenny AM. Prevalence of sarcopenia and predictors of skeletal muscle mass in healthy, older men and women. Journal of Gerontology. Medical Sciences 2002 57A M772-M777. (doi:10.1093/gerona/57.12.M772)

3 van den Beld AW, de Jong FH, Grobbee DE, Pols HA \& Lamberts SW. Measures of bioavailable serum testosterone and estradiol and their relationships with muscle strength, bone density, and body composition in elderly men. Journal of Clinical Endocrinology and Metabolism 200085 3276-3282. (doi:10.1210/jc.85.9.3276)

4 Szulc P, Claustrat B, Marchand F \& Delmas PD. Increased risk of falls and increased bone resorption in elderly men with partial androgen deficiency: the MINOS Study. Journal of Clinical Endocrinology and Metabolism 200388 5240-5247. (doi:10. 1210/jc.2003-030200)

5 Roy TA, Blackman MR, Harman SM, Tobin JD, Schrager M \& Metter EJ. Interrelationships of serum testosterone and free testosterone index with FFM and strength in aging men. American Journal of Physiology. Endocrinology and Metabolism 2002283 E284-E294. (doi:10.1152/ajpendo.00334.2001) 
6 Orwoll E, Lambert LC, Marshall LM, Blank J, Barrett-Connor E, Cauley J, Ensrud K \& Cummings SR. Endogenous testosterone levels, physical performance, and fall risk in older men. Archives of Internal Medicine 2006166 2124-2131. (doi:10.1001/archinte. 166.19.2124)

7 Bhasin S, Storer TW, Berman N, Callegari C, Clevenger B, Philips J, Bunnell TJ, Tricker R, Shirazi A \& Casaburi R. The effects of supraphysiologic doses of testosterone on muscle size and strength in normal men. New England Journal of Medicine 1996335 1-7. (doi:10.1056/NEJM199607043350101)

8 Morley JE, Perry HM III, Kaiser FE, Kraenxle D, Jensen J, Houston K, Mattammal M \& Perry HM Jr. Effects of testosterone replacement therapy in old hypogonadal males: a preliminary study. Journal of the American Geriatrics Society 199341 149-152.

9 Sih R, Morley JE, Kaiser FE, Perry HM III, Ping P \& Ross C. Testosterone replacement in older hypogonadal men: a 12-month randomized controlled trial. Journal of Clinical Endocrinology 1997 82 1661-1667. (doi:10.1210/jc.82.6.1661)

10 Synder PJ, Peachey H, Hannoush P, Berlin JA, Loh L, Lenrow DA, Holmes JH, Dlewati A, Santanna J, Rosen CJ \& Strow BL. Effects of testosterone treatment on body composition and muscle strength in men over 65 years of age. Journal of Clinical Endocrinology and Metabolism 199984 2647-2653. (doi:10.1210/jc.84.8.2647)

11 Tenover JS. Effects of testosterone supplementation in the aging male. Journal of Clinical Endocrinology and Metabolism $1992 \mathbf{7 5}$ 1092-1098. (doi:10.1210/jc.75.4.1092)

12 Katznelson L, Finkelstein JS, Schoenfeld DA, Rosenthal DI, Anderson EJ \& Klibanski A. Increase in bone density and lean body mass during testosterone administration in men with acquired hypogonadism. Journal of Clinical Endocrinology and Metabolism 199681 4358-4365. (doi:10.1210/jc.81.12.4358)

13 Urban RJ, Bodenburg YH, Gilkison C, Foxworth J, Coggan AR, Wolfe RR \& Ferrando A. Testosterone administration to elderly men increases skeletal muscle strength and protein synthesis. American Journal of Physiology. Endocrinology and Metabolism 1995 269 E820-E826.

14 Wang C, Swerdloff RS, Iranmanesh A, Dobs A, Snyder PJ, Cunningham G, Matsumoto AM, Weber T, Berman N \& Testosterone Gel Study Group. Transdermal testosterone gel improves sexual function, mood, muscle strength, and body composition parameters in hypogonadal men. Journal of Clinical Endocrinology and Metabolism 200085 2839-2853. (doi:10. $1210 /$ jc. 85.8.2839)

15 Szulc P, Duboeuf F, Marchand F \& Delmas PD. Hormonal and lifestyle determinants of appendicular skeletal muscle mass in men: the MINOS Study. American Journal of Clinical Nutrition 2004 80 496-503.

16 Vandenput L, Mellstrome D, Karlsson MK, Orwoll E, Labrie F, Ljunggren $\mathrm{O} \&$ Ohlsson C. Serum estradiol is associated with lean mass in elderly Swedish men. European Journal of Endocrinology 2010162 737-745. (doi:10.1530/EJE-09-0696)

17 Yaffe K, Lui LY, Zmuda J \& Cauley J. Sex hormones and cognitive function in older men. Journal of the American Geriatrics Society 200250 707-712. (doi:10.1046/j.1532-5415.2002.50166.x)

18 Morley JE, Kim MJ \& Haren MT. Frailty and hormones. Reviews in Endocrine and Metabolic Disorders 20056 101-108. (doi:10.1007/ s11154-005-6722-9)

19 Auyeung TW, Kwok T, Lee J, Leung J, Leung PC \& Woo J. Functional decline in cognitive impairment - the relationship between physical and cognitive function. Neuroepidemiology 2008 31 167-173. (doi:10.1159/000154929)

20 Orwoll E, Blank JB, Barrett-Connor E, Cauley J, Cummings S, Ensrud K, Lewis C, Cawthon PM, Marcus R, Marshall LM, McGowan J, Phipps K, Sherman S, Stefanick ML \& Stone K. Design and baseline characteristics of the osteoporotic fractures in men (MrOS) study - a large observational study of the determinants of fracture in older men. Contemporary Clinical Trials 200526 569-585. (doi:10.1016/j.cct.2005.05.006)

21 Lau EM, Leung PC, Kwok T, Woo J, Lynn H, Orwoll E, Cummings S \& Cauley J. The determinants of bone mineral density in Chinese men-results from MrOS (Hong Kong), the first cohort study on osteoporosis in Asian men. Osteoporosis International $2006 \mathbf{1 7}$ 297-303. (doi:10.1007/s00198-005-2019-9)

22 Wang L, Larson EB, Bowen JD \& van Belle G. Performance-based physical function and future dementia in older people. Archives of Internal Medicine 2006166 1115-1120. (doi:10.1001/archinte. 166.10.1115)

23 Heymsfield SB, Smith R, Aulet M, Bensen B, Lichtman S, Wang J \& Pierson RN Jr. Appendicular skeletal muscle mass: measurement by dual-energy X-ray absorptiometry. American Journal of Clinical Nutrition $1990 \mathbf{5 2} 214-218$.

24 Auyeung TW, Lee JS, Leung J, Kwok T, Leung PC \& Woo J. Survival in older men may benefit from being slightly overweight and centrally obese - a 5-year follow-up study in 4,000 older adults using DXA. Journals of Gerontology Series A: Biological Sciences and Medical Sciences 2010 65A 99-104. (doi:10.1093/gerona/glp099)

25 Melton LJ, Khosla S, Crowson CS, O'Connor MK, O'Fallon WM \& Riggs BL. Epidemiology of sarcopenia. Journal of the American Geriatrics Society $2000 \mathbf{4 8} 625-630$.

26 Labrie F, Belanger A, Belanger P, Berube R, Martel C, Cusan L, Gomez J, Candas B, Castiel I, Chaussade V, Deloche C \& Leclaire J. Androgen glucuronides, instead of testosterone, as the new markers of androgenic activity in women. Journal of Steroid Biochemistry and Molecular Biology 200699 182-188. (doi:10. 1016/j.jsbmb.2006.02.004)

27 Vandenput L, Labrie F, Mellstrom D, Swanson C, Knutsson T, Peeker R, Ljunggren O, Orwoll E, Eriksson AL, Damber JE \& Ohlsson C. Serum levels of specific glucuronidated androgen metabolites predict BMD and prostate volume in elderly men. Journal of Bone and Mineral Research 200722 220-227. (doi:10. 1359/jbmr.061018)

28 Alfaro-Acha A, Snih SA, Raji MA, Kuo YF, Markides KS \& Ottenbacher KJ. Handgrip strength and cognitive decline in older Mexican Americans. Journals of Gerontology Series A: Biological Sciences and Medical Sciences 2006 61A 859-865.

29 Atkinson HH, Rosano C, Simonsick EM, Williamson JD, Davis C, Ambrosius WT, Rapp SR, Cesari M, Newman AB, Harris TB, Rubin SM, Yaffe K, Satterfield S, Kritchevsky SB \& Health ABC Study. Cognitive function, gait speed decline, and comorbidities: the health, aging, and body composition study. Journals of Gerontology Series A: Biological Sciences and Medical Sciences 2007 62 844-850.

30 Fraley GS \& Ulibarri CM. Long-term castration effects motorneuron size but no number in the spinal nucleus of the bulbocavernosus in the adult male Mongolian gerbil. Brain Research 2002953 265-271. (doi:10.1016/S0006-8993(02) 02949-9)

31 Park JJ, Zup SL, Verhovshek T, Sengelaub DR \& Forger NG. Castration reduces motornueron soma size but not dendritic length in the spinal nucleus of the bulbocavernosus of wild-type and BCL-2 overexpressing mice. Journal of Neurobiology 200253 403-412. (doi:10.1002/neu.10103)

32 Callewaert F, Venken K, Ophoff J, De Gendt K, Torcasio A, van Lenthe GH, Van Oosterwyck H, Boonen S, Bouillon R, Verhoeven G \& Vanderschueren D. Differential regulation of bone and body composition in male mice with combined inactivation of androgen and estrogen receptor- $\alpha$. FASEB Journal 200923 232-240. (doi:10.1096/fj.08-113456)

33 Brown M, Ning J, Ferreira JA, Bogener JL \& Lubahn DB. Estrogen receptor- $\alpha$ and $-\beta$ and aromatase knockout effects on lower limb muscle mass and contractile function in female mice. American Journal of Physiology. Endocrinology and Metabolism 2009296 E854-E861. (doi:10.1152/ajpendo.90696.2008)

34 Vandenput L, Boonen S, Van Herck E, Swinnen JV, Bouillon R \& Vanderschueren D. Evidence from the aged orchidectomized male rat model that $17 \beta$-estradiol is a more effective bone-sparing and anabolic agent than $5 \alpha$-dihydrotestosterone. Journal of Bone and Mineral Research 200217 2080-2086. (doi:10.1359/jbmr.2002. 17.11.2080)

35 Orwoll ES, Nielson CM, Labrie F, Barrett-Connor E, Cauley JA, Cummings SR, Ensrud K, Karlsson M, Lau E, Leung PC, 
Lunggren O, Mellström D, Patrick AL, Stefanick ML, Nakamura K, Yoshimura N, Zmuda J, Vandenput L, Ohlsson C \& for the Osteoporotic Fractures in Men (MrOS) Research Group . Evidence for geographical and racial variation in serum sex steroid levels in older men. Journal of Clinical Endocrinology and Metabolism 2010 95 E151-E160. (doi:10.1210/jc.2009-2435)

36 Kim J, Heshka S, Gallagher D, Kotler DP, Mayer L, Albu J, Shen W, Freda PU \& Heymsfield SB. Intermuscular adipose tissue-free skeletal muscle mass: estimation by dual-energy X-ray absorptiometry in adults. Journal of Applied Physiology 2004 97 655-660. (doi:10.1152/japplphysiol.00260.2004)

37 Sartorius G, Ly LP, Sikaris K, McLachlan R \& Handelsman DJ. Predictive accuracy and sources of variability in calculated free testosterone estimates. Annals of Clinical Biochemistry 200946 137-143. (doi:10.1258/acb.2008.008171)

38 Mazer NA. A novel spreadsheet method for calculating the free serum concentrations of testosterone, dihydrotestosterone, estradiol, estrone and cortisol: with illustrative examples from male and female populations. Steroids 20094 512-519. (doi:10. 1016/j.steroids.2009.01.008)

39 Endogenous Hormones and Breast Cancer Collaborative Group. Free estradiol and breast cancer risk in postmenopausal women: comparison of measured and calculated values. Cancer Epidemiology, Biomarkers and Prevention 200312 1457-1461.

40 Rinaldi S, Geay A, Déchaud H, Biessy C, Zeleniuch-Jacquotte A, Akhmedkhanov A, Shore RE, Riboli E, Toniolo P \& Kaaks R. Validity of free testosterone and free estradiol determinations in serum samples from postmenopausal women by theoretical calculations. Cancer Epidemiology, Biomarkers and Prevention 200211 1065-1071.

Received 9 January 2011

Accepted 23 February 2011 